.Research Article

\title{
A Criminological Examination of the Use of Cyberspace to Traffic Drugs in Durban South Africa
}

\author{
Ms. Trevonia Nihal \\ University of KwaZulu Natal, South Africa \\ Department of Criminology and Forensic Studies \\ Dr.Ephraim Kevin Sibanyoni \\ University of KwaZulu Natal, South Africa \\ Department of Criminology and Forensic Studies \\ Private Bag X1, Golf Road Campus, Scottsville, Pietermaritzburg \\ SibanyoniE@ukzn.ac.za
}

\begin{abstract}
This study focused on the use of cyberspace to traffic drugs in Durban, South Africa. The study seeks to determine how cyberspace is used as a tool to traffic drugs in Durban, South Africa; to investigate the current South African laws as deterrence to combat drug trafficking via cyberspace. The studyused the qualitative research method. The data was collected from a sample consisting of eight respondents using the purposive sampling technique. The researchers collected data using semi-structured interviews and the collected data was analyzed through thematic content analysis. The findings depicted that cyberspace is used as a tool to traffic drugs in Durban by providing cyberspace users with the platform to engage in unlimited and secure communication. The use of Virtual Private Networks and The Onion Ring makes it exceptionally difficult to trace cybercriminals. Recommendation: There is a need for more awareness around cybercrime and, more particularly, drug trafficking via cyberspace. More law enforcement officers should be provided with training regarding cyberspace and drug trafficking via cyberspace.
\end{abstract}

KeyWords:Cyberspace,CybercrimeDrugs,DrugTrafficking,Cryptomarkets,Cryptocurrcy.

\section{Introduction:}

Drug trafficking via cyberspace has become an increasingly prevalent issue in contemporary South Africa (Alfreds 2018). The importance of understanding the trafficking of drugs in South Africa has been necessary and crucial for many years. However, numerous studies that were conducted have only proven that the drug trade evolves continuously, if not every day (Rademeyer 2013). A few years ago, online drug trafficking was not heard of but now the internet has become a tool and place for criminal activities such as drug trafficking via cyberspace (Elkhourly 2017).
According to the 2017 Global Drug Survey, 58\% of people reported buying drugs online and one in four $(25 \%)$ of those who used drugs in the past year had bought their drugs from underground marketplaces on the darknet (Global Drug Survey 2017). Since 2014, the number of users who purchased their drugs online has increased from $12 \%$ to $25 \%$ (Southwick 2018). The reason for such an increase could be the rise in the awareness of encrypted browsers on the deep web as well as for cryptocurrencies such as Bitcoin that are difficult for law enforcement to trace (Elkhourly2017).

Hoorens (2016) highlights that online drug 
Dr.Ephraim Kevin Sibanyoni et.al/A Criminological Examination of the Use of Cyberspace to Traffic Drugs in Durban South Africa trafficking may be an aid for offline drug trafficking (buying drugs on the street). According to Hoorens (2016), compared to the days of Silk Road in 2013, the number of transactions of illegal drugs on cryptomarkets has tripled and the revenue has doubled. This provides proof that drugs are being bought in bulk online only to be sold on the street. According to Monama (2018), 25\% of total drug transactions on cryptomarkets during January 2016 were of a value of more than 1,000 US dollars (indicating that they were purchased online to be sold on the street), while the majority of drugs sold on cryptomarkets under 100 US dollars in value was $18 \%$ (most likely for personal use). The findings of Monama (2018) confirm the statement of Hoorens (2016), in that a larger percentage of drugs were bought in bulk only to be sold to people on the street. A Global Drug Survey conducted in 2017 stated that only $5 \%$ of the respondents bought drugs online. However, when the survey was conducted in 2015 , this number increased to $25 \%$ of respondents who purchased drugs online. According to the World Health Organization's drug statistics on South Africa, $15 \%$ of the population has a drug addiction whilstthe United Nations' statistics revealed that South Africa is ranked fourth globally for drug offense cases per 100,000 people. According to Rall (2017), South Africa is the largest market for illicit drugs in sub-Saharan Africa, with the use and trafficking of drugs increasing steadily. In June 2017, $963 \mathrm{kgs}$ of cocaine (worth roughly 23 million US dollars) were seized in Cape Town, South Africa (Rall 2017). This is one of the largest seizures in the country to date. Despite the seizures of drugs, there is still much work that needs to be done in curbing drug trafficking online. South African law enforcers have limited expertise concerning cyber-crime. There is only one cybercrime unit for the entire country and is based in the capital city with limited resources and very few officers. This limitation makes it impossible to facilitate preventative measures that are effective to curb this criminality. Thus the purpose of this paper is to depict the perceptions of the police officers who are in the cyber-crime unit about how drugs are being trafficked using cyberspace in Durban SA and to explore deterrence mechanisms in place to deal with this type of crime.

\section{Theoretical Framework:}

The researchers applied this theory (classical school of thought) to attempt to explain why certain

individuals embark on trafficking drugs using cyberspace and/or embarking on dealing with drugs. The researcher used this theory's principles to explain the commission of this crime.

\subsection{The Classical School Of Thought In An Attempt To Explain Drug Trafficking Using Cyberspace:}

The Classical School of Thought emphasizes the free will to offend coupled with rational choice. Drug traffickers make their own decisions and choices that are based on free will. They are aware of the consequences involved (this includes fines, confiscation of drugs, criminal record, and imprisonment) and the gain they shall receive in dealing with the drug over cyberspace. The researchers are of the opinion that drug traffickers offend because of the free will that they possess. They have the free will to choose to traffic drugs based on the calculated reward of trafficking and the punishment. The moral wrongdoing is fed by their personal choice to participate in the crime. These individuals are conscious agents who are unaffected by internal (lack of conscience and morals) or external forces (punishment, laws, judiciary) (Tierney 2009). For this reason, their interest lies only in the attainment of their goals, which is usually monetary. Cesare Beccaria's theory was that criminals have control over their behavior, they choose to commit crimes and they can be deterred by the threat of punishment. Using Beccaria's theory, we can explain drug trafficking as a choice that individuals make. Irrespective of purchasing, selling or distributing drugs, it is all a choice made by the person. Such people are driven by the idea of "easy money" and they are not concerned with the manner in which they have to achieve this (West 2017).According to the Classical School of Thought, the individual weighs the pros and cons of committing a particular crime (Freilich 2015). The person calculates whether the potential pleasure from trafficking drugs is worth the potential punishment. This is where the idea of rational thinking is crucial. One of the features of the theory, hedonistic calculus, explains that the individual will make a decision to commit the crime (online drug trafficking) when there are maximum pleasure and minimum pain. With drug trafficking, the offender knows that it is easier to traffic drugs as there is more money involved than any ordinary job. In other words, there is a maximum amount of money being received with little work being done. It is the 
Dr.Ephraim Kevin Sibanyoni et.al/A Criminological Examination of the Use of Cyberspace to Traffic Drugs in Durban South Africa ultimate gratification that the drug trafficker seeks from committing the crime of online drug trafficking. This theory can also explain online drug trafficking in terms of opportunity, costs, and benefits when considering the offenders' decision to commit the crime. With the innate ability to think rationally and naturally want to attain more pleasure than pain (the pleasure being money and the pain being punishment), the internet provides the criminal with ample opportunity, which is also costeffective, to commit a crime such as online drug trafficking. With the internet being readily available and anonymity being an automatic benefit, there is a wide range of economic choices available for the criminal to take advantage of. The Classical School of Thought explains drug trafficking in that the crime is committed with the offender being fully aware of what he or she is doing, regardless of the reason that he or she is doing it. Clearly, the fact that the person has made the decision to commit such a crime means that he or she has assessed and weighed the risks and rewards involved. The researchersare of the opinion that despite being rational, it is human nature to rather follow, which provides gratification and reward than to logically assess individual behavior as being wrong or immoral. Even if it means that the consequences or risks are more than the reward, individuals may still take the opportunity to traffic drugs via cyberspace, especially if they have already made a firm decision on trafficking drugs. Individuals use their own knowledge and understanding to examine the options available and then choose the action that holds the maximum benefit for them. In this way, individuals only consider the consequences that their actions will have on themselves and do not take the effect of those actions on other people into account.

\section{Methodologies:}

According to Kraska and Neuman (2008), an exploratory research design is used when a new area or topic is being investigated or when little is known about an area of interest. The exploratory research design examines the relevant factors of the phenomenon in detail so as to arrive at an appropriate description of the existing problem (Malterud, Siersma\&Guassora 2016). This research design is used to investigate the nature of the phenomenon in question as well as its surrounding factors such as the beneficiaries of online drug trafficking. In this study, the researchers explored

the use of cyberspace as a tool for traffic drugs in Durban. An exploratory research design was used as this research design study phenomena, such as online drug trafficking, which has not otherwise been intensively studied in the Durban area. It aids the researchers in exploring the area of research and thus discovering new meanings and understandings related to the study (Bachmann \&Schutt 2008). According to Baxter and Jack (2008), the results from an exploratory study may not necessarily be generalizable to a larger population but they do provide a better understanding of the sample that is being examined.

\subsection{Sampling:}

The sample size for this study comprised 8 respondents (police officers from the South African Police Services Cybercrime Unit). This small sample was due to the sensitivity and elusive nature of the study and was the only available amount of officers in the unit at the time of this study. However, this did not affect the study as the eight respondents who were interviewed provided as much information that they could and to the best of their knowledge and experience. These respondents were chosen as they are central to the study and formed a major category of individuals who are involved in the research topic area, that being cybercrime. The sample consisted of only male officers from all races and age groups who hadfirsthand experience with cybercrime and online drug trafficking. These respondents were selected by means of purposive sampling. Purposive sampling is a sampling technique in which the researcher relies on his/her own judgment when choosing members from a population to participate in the study (Dudovskiy 2017). Purposive sampling technique is the most cost-effective and time-effective sampling method andan appropriate method that is available if there are a limited number of participants who can serve as primary data sources, as was the case in this study (Dudovskiy 2017). According to Neuman (2000), there are two main situations in which the researcher would consider using purposive or judgment sampling: one is when the researcher uses it to select cases that are specifically informative to the study, and the other is when the information provided by the respondent is relevant to the study. The researchers chose purposive sampling based on the assertions presented by Neuman (2000).

\subsection{Data Collection:}


Dr.Ephraim Kevin Sibanyoni et.al/A Criminological Examination of the Use of Cyberspace to Traffic Drugs in Durban South Africa

The researchers use primary data, which took place in the form of semi-structured interviews with cybercrime unit officers. The interviews were oneon-one and varied in length. The researchers used probing questions toobtain further insights from the respondents.Informed consent were solicited from the respondents prior to the commencement of the interview and they were ensured that their confidentiality would be maintained and that they would remain anonymous. The semi-structured interviews were chosen to ensure that the respondents were at ease and were able to open up about their individual experiences and perceptions of cybercrime and online drug trafficking. This type of interview enabled the researchers to obtain rich information from the respondents without making them feel intimidated by the formal procedures otherwise associated with a structured interview.Another intended outcome of conducting semi-structured interviews was to attempt to gather and gain an understanding of how police officials in the cybercrime division experience cybercrime and how that shapes their perception of it. The time of participation for the interview was negotiated between the participant, the commissioner of the cybercrime division and the researchers to ensure that the interview was scheduled at a time of convenience for the officers. For this reason, the interviews were mainly conducted at a time whereby the officers were free and available to be interviewed. The venue was negotiated with each participant and offices within the SAPS cybercrime division were mainly used as it is a setting that the officers are familiar with and most likely feel comfortable in. The interviews were initially calculated to be $30-45$ minutes long but this varied amongst each respondent in the field during the process of data collection.

\subsection{Data Analysis:}

The data collected was analyzed using thematic content analysis (Patton 2005). The researchers familiarised themselves and immersed themselves with the data. Transcripts or recordings werereviewed several times. Then generatedand/or identified initial codes or themes that appear interesting and meaningful to online drug trafficking. Thereafter, the themes were named and defined. Lastly, the researchers transformed the analysis into an interpretable report.

\section{Results And Discussions:}

This section of the paper presents the results and discusses the findings of the study.The " $R$ " in brackets refers to the "Respondent(s)"

\subsection{Cyberspace As A Tool To Traffic Drugs In Durban South Africa:}

The study finds that cyberspace is used as a tool to traffic drugs in Durban by allowing certain sites to exist in an area of the web that is only accessed for the means of illegal activities such as online drug trafficking. The existence of the dark web and dark web marketplaces are the very reason that cyberspace is used as a tool to traffic drugs in Durban. The police officers from the cyber unit were asked to provide an opinion of how cyberspace is used as a tool to traffic drugs in Durban. The data revealed various reasons for how cyberspace is used as a tool to traffic drugs in Durban. One reason that resonated amongst all the police was that cyberspace is used as a communication platform for criminals."Cyberspace, I think is a tool because communication is not only voice-related, it's also done through electronic media and electronic media is also a tool which translates information which is then used to commit that particular crime' (R2)

'It may not be committed in terms of tangible things but in terms of communication because every crime starts with communication. Communication is one through cyberspace and after it has been agreed upon the manner or method of deliverance and so on and that's where we can say the crime is committed there. So delivery and also instructions on the crime are also done there. So the place and the person are only given instructions by means of cyber communication' (R1)

Respondent one had indicated that social media, which has to be accessed via the internet, is how cyberspace may be used as a tool. He continued by stating: 'Uhm, social media can be used. We've got the deep web as well where criminals may use that platform to sell their trade or to sell their whatever narcotics that they are having'

The criminals use the deep web as their platform to sell their drugs. This is in accordance with the findings by Peek (2015) which stated that various layers of the internet (that is the deep web and dark web) allow for crimes, like that of drug trafficking, to take place via cyberspace. Cyberspace creates an open portal for drugs to travel from one person to another without knowing the person that is involved with the selling or buying of drugs.

The study also finds that cyberspace is used as a tool 
Dr.Ephraim Kevin Sibanyoni et.al/A Criminological Examination of the Use of Cyberspace to Traffic Drugs in Durban South Africa

to traffic drugs in Durban in that it aids in finding customers to sell drugs to as well as finding suppliers of drugs. It is evident that cyberspace is used as an aid or facilitation of communication, it is also acknowledged that there are other ways that cause cyberspace to be used as a tool to traffic drugs in Durban (this includes advertising and finding suppliers and distributors). Cyberspace becomes an online market not just for drug dealers and users but it also creates a niche for suppliers to make contact with dealers. The connections for illegal dealings via cyberspace is limitless. According to Drug Rehab (2018), online drug trafficking has been on the increase because the sites on the dark web marketplaces allow people to buy drugs anonymously and to make use of Bitcoin which proves challenging to trace. Bitcoin is becoming increasingly user-friendly thus allowing more internet users to partake in illegal online activities such as drug trafficking. The authors opine that online drug trafficking using cyberspace as a tool is on the increase because it is safer than face-to-face purchasing of drugs where individuals may be subject to being robbed or assaulted. Online marketplaces are also exempt from random police searches in comparison to regular street dealers and users that may be subject to random raids and searches.One reason that may be self-deductive is that there is an overall increase in the use of drugs hence the increase in online drug sales.Police officers (respondents) were asked as to how cyberspace as a tool increases the trafficking of drugs. Their responses confirmed several of the reasons for this increase in online drug trafficking:

'Well, tracing them may prove as a challenge because you can assume any identity on the internet without being validated so it is a challenge and this is what causes the crime to increase' (R1)

'Cyberspace is borderless so irrespective if you have ever met or never met but as long as you can google and go into dark webs to communicate or check sites or anything you want to utilize to communicate with a specific person, that's where you can do the networking and through further communication, you can determine which person to do certain business with and that's where the internet can be utilized to increase crimes like drug trafficking' (R2).

'The ease of access, the person no longer has to travel from block A to B or use my own transport. The ease of use and ease of access. And it's also cheaper and quicker. You can contact a person in Cape Town, without driving there and looking for him' (R3).'To the individuals/organizations competent in digital-anti-tracking techniques, cyberspace lends an aspect of anonymity. This "cloaked" environment makes the advertising of, communication regarding, transactions and logistics related to illicit activities much easier than previously employed methodology' (R5)From the above responses, it can be established that because of anonymity, tracing on the internet can prove to be extremely difficult thus causing the crime to increase. Important to note is that Durban currently lacks the proper technological tool to trace individuals' digital footprint. With online tracking making it difficult to track down cybercriminals, it inevitably opens a way for these criminals to make use of such a platform to commit their crimes. There is an "ease of access", which can be attributed to the fact that the internet is at our fingertips almost, if not, all the time. Cyberspace increases drug trafficking because it is cheaper and quicker. This can be confirmed by the work of Lusher (2016) who stated that individuals make use of the internet to traffic drugs because it is a much more efficient means of getting drugs in terms of logistics and at a slightly reduced price. Lusher (2016) goes further to state that an order is placed and a few days later, the drugs are received. It can be deduced that this increase is being reinforced by means of confidentiality and that anonymity plays a major role in the increase of online drug trafficking in Durban. It is clear that there is no one single reason that cyberspace increases drug trafficking but rather that there are several contributors to the increase of online drug trafficking in Durban (such as the ease of access to the internet, difficulty in tracing, cheaper and quicker service and the borderless characteristic of cyberspace).

\subsection{Precipitating Factors For Online Drug Trafficking In Durban:}

According to Malenkovich (2012), money may be the main motivator for cybercriminals as it is often "easy money". While each cybercriminal may have their own personal reason to commit online drug trafficking or any other cybercrime for that matter, most of them commit this crime for the financial gain as drug trafficking via cyberspace is of low risk and detection as mentioned in the literature of chapter two. A study conducted in Germany revealed that more than $65 \%$ of respondents indicated that cybercriminals conduct online drug trafficking because of the money. The same study 
Dr.Ephraim Kevin Sibanyoni et.al/A Criminological Examination of the Use of Cyberspace to Traffic Drugs in Durban South Africa conducted in the United States revealed that $63 \%$ of respondents felt that money was the main reason for online drug trafficking (Malenkovich 2012). This reason is supported by The Classical School of Thought which explains that cybercriminals weigh the advantages against the disadvantages when committing the crime of online drug trafficking. Many of the respondents shared the view that money or financial gain is the leading reason and/or factor that individuals resort to online drug trafficking. 'The primary motive for people selling or rather committing the crime is to make money. Social media has also brought a culture of showing off material things so to an ordinary person, if he gets approached to commit this type of crime and he weighs the pros and cons, he may consider trafficking to make money' (R1). 'People can also be enticed to do this crime because the money may be good. It is sometimes very difficult to find jobs so some people may see this as an escape or solution to their problems' (R2). 'It's because of money-wise. Because drugs are a lucrative business and that's why they get into drugs. The people who are recruiting all these drug mules are targeting all the low class and low-income people who have nothing. They offer R10 to do this, the person will think it's a quick and easy R10 and do it' (R7)Respondents believe that money is the first and foremost the reason that cybercriminals are trafficking drugs and due to the fact that cyberspace provides a safer platform. Mathews (2017) arrived at the same conclusion, he stated that cyberspace creates an environment that is safe and protected by layers of encryption thus making cybercrimes like drug trafficking more difficult to detect. Individuals that purchase or sell drugs online via cyberspace are less likely to be subject to random searching or suspicion in comparison to normal street drug dealers and users. Respondent three stated that:'Firstly, for me, why people commit crimes, especially drug-related, is because of money which is again. Secondly, they will look at the chances of being caught. When you commit a crime, you obviously evaluate. If I take chances and I'm caught then I'm in trouble so in the event of the cyberspace, it creates a safer platform hence they commit this crime'

Respondents stipulated that online drug traffickers commit this crime because of material gain and not just financial gain alone. While these individuals may not be using the drugs that they traffic, they certainly sell them to get the material possessions that they want without having to put in the effort and work tirelessly for it. Cybercriminals are willing to make the decision on their own and commit to the risks of drug trafficking because they are aware that the financial gain from their illegal activities is greater than that of maintaining a legal job. Respondent five stated: 'In my professional experience, addicts, however, they may have been introduced to drug abuse, are pressured to continue by virtue of their addiction. Traffickers are not necessarily addicts/users, but engage in this practice for personal material gain'In addition to this, respondent six added a new area of the reason for the crime of online drug trafficking. While stipulating the norm of this theme, which is monetary gain, he had also indicated other reasons as to why an individual would engage in drug trafficking via cyberspace. In his response, he states that: 'Could be peer pressure and wanting to be a part of something. The lack of finances also causes people to want to do this crime, it is an easy way out. People who don't have a lot of things may want quick money to buy certain material goods. Also, poverty leads peoples to commit a crime'

The response above highlights that peer pressure and poverty may be the reasons as to why some individuals engage in online drug trafficking in Durban. A study conducted by Pokhrel (2015), revealed that more than half the crime that was drug-related from 2012 to 2014 was due to peer pressure. Furthermore, Pokhrel (2015) states that between July 2012 and July 2014, 15\% of drugrelated crimes were committed because of poverty. This confirms that while many people traffic drugs via cyberspace for money or material gain, there are also other factors such as peer pressure and poverty that contribute to this crime especially in contemporary Durban where peer pressure and poverty are rife in several communities. It is evident that money is the leading factor that motivates people to traffic drugs via cyberspace in Durban. However, there are also other factors such as peer pressure, poverty and personal choice that affects an individual's decision to engage in online drug trafficking in Durban. This was consistent with the findings of the study conducted by Pokhrel (2015) and well as Esiri (2016) whose research revealed peer pressure, poverty, and individual choice as reasons for crimes such as online drug trafficking.

\subsection{Deterrence Online Drug Trafficking In Durban:}

It is often believed that harsher or longer sentences 
Dr.Ephraim Kevin Sibanyoni et.al/A Criminological Examination of the Use of Cyberspace to Traffic Drugs in Durban South Africa

have a direct effect on lowering the amount of crime. However, Adwar (2014) states that while this may work in certain instances, it is not always the case. The researchers are of the view that the reason behind this narrative is the belief that punishing a person, will make him/her less likely to commit the action that led to the punishment (in this instance, drug trafficking via cyberspace).The respondents were of the view that harsher punishment can deter drug trafficking via cyberspace. The verbatim as follows:'Yes it would but then we must also focus on end-users because if there is no market for drug peddlers, they will end up with a product that is useless to them so more focus should also be on the end-users. Better rehabilitation and better awareness programs should be there, a better relationship between law enforcement and the communities' (R1).'I think that yes it will contribute to the reduction of the crime. Not to state that it will make drug trafficking fade away but harsher sentences will make a difference especially to the traffickers but not necessarily to the users' (R3)'Yes, it would. If the punishment is increased then definitely it would. Harsher sentence. 2-4 years for smuggling $2 \mathrm{~kg}$ of uncut cocaine. That $2 \mathrm{~kg}$ of uncut cocaine, you make $6 \mathrm{~kg}$ so how many lives are being destroyed? So I would definitely say that harsher punishment should be given for that' (R7).

'Yes that will do. Why I'm saying this is because if they say you are found committing a crime such as a drug trafficking, you are going to be convicted to a life sentence or death sentence, I should think that it would curb crimes such as this' (R8).

From the responses above, it is evident that harsher punishment would curb crimes such as online drug trafficking. On the contrary, there are other respondents who believe otherwise. They did not believe that harsher punishment would curb drug trafficking via cyberspace, they believe that the cybercriminals would go back to old habits despite harsher punishment. 'Harsher punishment may remove the dealers or others involved but this may not curb the problem. As people are addicted to drugs, there are others addicted to selling them. In current time, drugs are even found in prison so there is no surety that harsher punishment will stop or curb drug trafficking' (R2)'How harsh can you really punish a person. Sometimes it won't change them' (R4)'For some, yes. But for many people, it won't because they will relapse into old habits especially if they are comfortable with finding money easily' (R6)

The respondents(50\%) strongly believe that harsher punishment will not curb online drug trafficking. They are of the view that despite harsher punishment, or longer sentences for that matter, there are still many that will go back to what they know best and that is to use cyberspace to traffic drugs. There should be greater use of reformation incorporated with the punishment that cybercriminals receive.

\section{Conclusion:}

Cyberspace is used to traffic drugs in Durban by allowing individuals to use cyberspace as a platform to communicate with the added benefit of anonymity and encryption. With this, cybercriminals are able to discuss various aspects of their drug trafficking enterprise (including prices, pick up locations and amount of drugs required) with ease and without being suspected of partaking in drug trafficking via cyberspace. Although there are three separate laws relating to drugs and drug trafficking, neither of these laws covered the aspect of cyberspace and drug trafficking under the same law. The Cybersecurity Bill, the Drugs and Drug Trafficking Act no. 140 of 1992 and the Medicines and Related Substances Act no. 90 of 1992. Each of these laws covers either cyberspace or drug trafficking but not drug trafficking using cyberspace. There is a legislative framework limitation in South Africa designed to specifically tackle the issue of trafficking drug-using cyberspace. Drug trafficking via cyberspace is not listed as a cybercrime within the cybersecurity Bill of which this needs to be amended and rectified.

South Africa is not efficiently equipped to prevent and resolve Cybercrime and more specifically, drug trafficking via cyberspace. This is due to the fact that we do not have properly trained law enforcement officers. Law enforcement officers need to be exposed and trained to deal with Cybercrime. Every officer of the law should be able to have the basic knowledge of this crime and how it occurs. There should have specialized task teams available that efficiently and effectively deal with Cybercrimes. 
Dr.Ephraim Kevin Sibanyoni et.al/A Criminological Examination of the Use of Cyberspace to Traffic Drugs in Durban South Africa

\section{References:}

1. Adwar, C., 2014. Here's evidence that insanely long prison terms are a bad way to deter crime, retrieved from https://www.businessinsider.com/report-sayslong-sentences-dont-deter-crime-2014-5?IR=T on $10^{\text {th }}$ September 2018.

2. Alfreds, D., 2018. Here's how cybercriminals are targeting attorneys in scams to steal cash, retrieved from https://www.fin24.com/companies/ICT on $17^{\text {th }}$ September 2018.

3. Bachman, R., \&Schutt, R.K., 2008. The Fundamentals of Research in Criminology and Criminal Justice, Sage publications, USA.

4. Baxter, P. \& Jack, S., 2008. Qualitative case study methodology: Study design and implementation for novice researchers. The qualitative report, 13(4), pp.544-559.

5. Drug Rehab, 2018. Online drug trafficking becoming alarming, retrieved from https://www.drugrehab.us/news/online-drugtrafficking-becoming-alarming/ on $\quad 3^{\text {rd }}$ September 2018.

6. Dudovskiy, J., 2017. Purposive Sampling, retrieved from https://www.researchmethodology.net/sampling-in-primary-datacollection/purposive-sampling/ on $6^{\text {th }}$ September 2017.

7. Elkhourly, L., 2017. Fighting drug trafficking online - The role of the internet in the NPS trade, retrieved from https://www.cocaineroute.eu/fighting-drugtrafficking-online-the-role-of-the-internet-in-thenps-trade on the $19^{\text {th }}$ of September 2018.

8. Esiri, M.O., 2016. The influence of peer pressure on criminal behavior,ISOR Journal of Humanities and Social Science, Vol 21.

9. Freilich, J.D., 2015. Beccaria and situational crime prevention. Criminal Justice Review, 40(2), pp.131-150.

10. Global Drug Survey, 2017. GDS 2017, retrieved from globaldrugsurvey.com/pastfindings/gds2017-launch/

11. Hoorens, S., 2016. Taking stock of the online drugs trade, retrieved from https://www.rand.org/randeurope/research/proje cts, on $18^{\text {th }}$ September 2018.

12. Kraska, P.B., \&Neuman, W.L., 2008. Criminal Justice and Criminology Research Methods, Pearson Education, USA.

13. Malenkovich, S., 2012. What motivates cybercriminals? Money, of course, retrieved from https://www.kapersky.com/blog/whatmotivates-cybercriminals-money-of-course/717/ on $6^{\text {th }}$ September 2018.

14. Malterud, K., Siersma, V.D. \&Guassora, A.D., 2016. Sample size in qualitative interview studies: guided by information power. Qualitative health research, 26(13), pp.1753-1760.

15. Mark, J.J., 2014, Silk Road, retrieved from https://www.ancient.eu on $14^{\text {th }}$ December 2017.

16. Mathews, L., 2017, What TOR is and why you should use it to protect your privacy, retrieved from

https://www.forbes.com/sites/leemathews/2017/ 01/27/what-is-tor-and-why-you-should-use-it-toprotect-your-privacy on 9th March 2018.

17. Monama, T., 2018. Beat cybercrime insecurity, retrieved from https://www.dailysun.co.za/success/health, on $18^{\text {th }}$ September 2018.

18. Monyakane, M., 2016. The South African Drugs and Drug Trafficking Act No. 140 of 1992, retrieved from https://www.linkspringer.com on $6^{\text {th }}$ May 2018.

19. Neuman, W.L., 2000. Social Research Methods: Quantitative and Qualitative approaches, Allyn\& Bacon, Needham Heights.

20. Patton, M.Q., 2005. Qualitative research. Encyclopedia of statistics in behavioral science.

21. Pokhrel, N., 2015. Peer pressure leading youth to crime, retrieved from https://www.kuensel.com/peer-pressure-leadingyouth-to-crime/ on $8^{\text {th }}$ September 2018.

22. Rall, S., 2017. SA slated as drug trade hub, retrieved from https://www.iol.co.za/news/saslated-as-drug-trade-hub-8130415 on $24^{\text {th }}$ September 2018.

23. Tierney, J., 2009. Key Perspectives in Criminology, Open University Press, New York.

24. West, R., 2017. Classical Criminology. The Wiley-Blackwell Encyclopedia of Social Theory, pp.1-4. 